\section{Ichthyologists all at sea}

\author{
Alwyne Wheeler
}

Fishes of the North-eastern Atlantic and the Mediterranean. Edited by P. J. P. Whitehead, M.-L. Bauchot, J.-C. Hureau, J. Nielsen and E. Tortonese. UNESCO: 1985-1987. Three volumes, pp. 1,473.* Smiths' Sea Fishes. Edited by M. M. Smith and P. C. Heemstra. Macmillan, South Africa/Springer-Verlag:1986. Pp. 1,047. R145, DM198.

THERE are estimated to be about 22,000 different species of fishes living today, more than those of all the other vertebrate groups put together. It is not surprising, then, that books attempting to catalogue all the fishes of a large area are now often multi-authored (and sometimes multivolumed). Each of the works reviewed here is the result of the efforts of around 70 authors, whose contributions have been edited to a consistent style in one case by a team of five editors, in the other by two.

Fishes of the North-eastern Atlantic and the Mediterranean is a set of three volumes designed for identification of all sea fishes in the area. It has keys for the identification of families (Vol. 1), and to genera within each family, and species within the genera; these are scattered through the text. Each species is illustrated and tersely described, notes are given on habitat, food and reproduction, and the distribution is mapped as well as described. The illustrations (all line drawings) are mostly reproductions of existing artwork. This is a concise but comprehensive account of the fishes of European seas, and of the deep sea to the west of Europe, which will be a standard source of reference for many years.

Smiths' Sea Fishes derives from the original Sea Fishes of Southern Africa by the late J. L. B. Smith. It is an impressive volume, co-edited by Smith's widow and P. C. Heemstra, and contains accounts of about 2,150 species which live in the seas around southern Africa. The treatment is largely taxonomic, with keys to identification and a short diagnosis of each species. Many species are illustrated with line drawings, others with monochrome photographs some of which, taken from earlier reproductions, are of poor quality. There are 144 colour plates comprising a number of drawings (retained from earlier

* In France available from Librairie de I'Unesco, 7 Place de Fontenoy, 75700 Paris; in Britain from HMSO, PO Box 276, London SW8 5DT; in the United States from Unipub, 4611F Assembly Drive, Lanham, Maryland 20706. Price of each volume is, respectively, FF $250, £ 37.50$ and $\$ 45$. editions of Smith's work) or new photographs. The colour illustrations occupy a discrete section of the book, making reference to them so much easier than in Sea Fishes of Southern Africa in which they were placed at random throughout the text.

Comparison with the original work of J. L. B. Smith is inevitable, although unjust in some ways because this is essentially a new book. By inviting an international team of authors to work on it, the editors have to a large extent avoided the elements of parochialism that were previously evident. There are still glimpses of the original however. For instance, the short essay on the sense of pain in fishes is a direct quotation and is an example of

\section{Conducted tours}

\section{P.N.Butcher}

Conduction in Non-Crystalline Materials. By Sir Nevill Mott. Clarendon: 1987. Pp.128. £17.50, \$22.36.

'SMALL is beautiful' is the maxim that Professor Mott has adopted in his new book. His aim is threefold. First, to provide an introduction for students of both experiment and theory. Secondly, to update the earlier and larger book written in collaboration with E.A. Davis (Electronic Processes in Non-Crystalline Materials, a second edition of which was published by Oxford University Press in 1979). Thirdly, to show how the ideas developed in studies of amorphous semiconductors can be applied to vitreous silica, amorphous metals, impurity bands in doped crystalline semiconductors and so on.

The result is a superb read which will be of great interest to anyone who has been associated with the developments in this rapidly expanding subject. The book is illuminated throughout by Professor Mott's physical insight into the materials and the processes that go on in them. Many questions are left unanswered because there are no answers. Therein lies the fascination - one is left thinking about what steps might be taken either in the laboratory or in calculations which could begin to lead towards a resolution of the many mysteries remaining in the behaviour exhibited by disordered conductors. This is the sort of intellectual stimulation that one has come to expect from Professor Mott, and he does not disappoint us.

Readers, however, will be screaming with frustration as one subject after another is brilliantly opened up only to be closed down so as to keep the book within its all-too-brief compass of 113 pages of text. There are copious references, but the experts will have read them already, while opinion promoted as fact. Thirty years after its first publication, there is considerable evidence for the presence of 'pain blockers' in fishes, as in higher vertebrates, to which it would have been reasonable to refer.

On its appearance in 1949 'J. L. B. Smith' was a trend-setting book, and down the years it has been a vital work of reference. The new Smiths' Sea Fishes will undoubtedly serve the same role for the next generation (or two) of ichthyologists. Its coverage is essentially the sea fishes of Africa south of the Equator, but it will be valuable far beyond that area.

Alwyne Wheeler is in the Department of Zoology, British Museum (Natural History), Cromwell Road, London SW7 5BD, UK.

students will rapidly lose themselves in a morass of conflicting views if they follow Professor Mott's directions to the primary literature.

There is a central difficulty which has to be faced in writing about conduction in non-crystalline materials. Even after two decades or more of vigorous research, no generally accepted quantitative model has emerged for any particular material. Tremendous progress has been made with the application of amorphous silicon to devices, following the discovery by the Dundee group that this semiconductor can be doped. There have also been great advances in our understanding of many of the details of electron transport in disordered materials. However, there has been little movement on the fundamental questions. What is the nature of the disorder in any particular material? How should it be described? How does the description of the disorder lead to an understanding of the physics of electron transport in that material? This is precisely why the subject continues to interest so many physicists. It is also why it is so difficult to describe in a textbook, particularly a short one.

Professor Mott reviews a great many questions. He provides some of the answers and points out where serious problems remain. Everyone interested in electron transport should acquire this book; students should have a copy of Mott and Davis to accompany it.

P.N. Butcher is a Professor in the Department of Physics, University of Warwick, Coventry CV4 $7 A L, U K$.

\section{New in paperback}

- Light and Photosynthesis in Aquatic Ecosystems by John T. O. Kirk. Publisher is Cambridge University Press. Price is $£ 15$, $\$ 24.95$. For review see Nature 309, 302 (1984). - Spinors and Space-Time, Vol. 1: Two-Spinor Calculus and Relativistic Fields by R. Penrose and W. Rindler. Publisher is Cambridge University Press. Price is $£ 17.50, \$ 29.95$. For review see Nature 313, 607 (1985). 